\title{
A MECHANICAL METHOD FOR DEFORMATION MEASUREMENT AND VISUALIZATION IN TUNNEL CONSTRUCTION
}

\author{
Haihua ZHANG ${ }^{1}$, Shinichi AKUTAGAWA², Yasuhisa AONO$^{3}$ \\ and Koji TSUJIMURA ${ }^{4}$ \\ ${ }^{1}$ Student member of JSCE, Graduate School of Eng., Kobe University \\ (Rokkodai 1-1, Nada-ku, Kobe 657-8501, Japan) \\ E-mail:haihua_1314@hotmail.com \\ ${ }^{2}$ Member of JSCE, Professor, Dept. of Civil Eng., Kobe University \\ (Rokkodai 1-1, Nada-ku, Kobe 657-8501, Japan) \\ E-mail:cadax@kobe-u.ac.jp \\ ${ }^{3}$ Shimizu Corporation \\ (Etchujima 3-4-17, Koto-ku, Tokyo 135-8530, Japan) \\ E-mail: y.aono@shimz.co.jp \\ ${ }^{4}$ Member of JSCE, SK-Lab Co., Ltd \\ (Nagayoshideto 8-1-14-B, Hirano-ku, Osaka 547-0011, Japan) \\ E-mail:tsujimura@sk-lab.com
}

\begin{abstract}
Deformation measurement is usually one of the key elements of measurement carried out in tunnel construction. A new mechanical method is proposed to measure the relative displacement between two points, and to visualize the results in real-time based on the concept of "On-site Visualization". The mechanism of the method lies in that a rotational structure is used to translate the linear displacement into the rotation. Since the simple method performs in a mechanical way without using electricity, it would reduce the purchase\&use cost to an acceptable degree.

This paper presents the laboratory tests and a field experiment to verify the possibility and feasibility of the method. In the field experiment, the shotcrete cracks, the heave of invert and so on in the tunnel during construction were monitored by this method. The measured results are analyzed in comparison with those from Total Station, which shows the deformation of the tunnel during construction could be detected and visualized availably. Finally, the applications of this mechanical method are discussed briefly.
\end{abstract}

Key Words : On-site Visualization, deformation measurement, mechanical method

\section{INTRODUCTION}

Deformation monitoring plays an important role in tunnel construction because it provides a basis for the safety assessment of the tunnel structure and optimization of the construction parameters for the next excavation stage. Many instruments, such as the extensometer, Total Station, and digital image processing technology device, have been applied to the deformation measurement to help the safety management of the construction ${ }^{1), 2}$.

For conventional measuring methods, as shown in Fig.1, it takes time to report the measured results to the persons involved at the construction site. However, it is essential to take actions on site as early as possible if there would be an accident during construction. Thus, a method capable of providing realtime measurement and instant data-presentation is needed to distribute information directly to the onsite workers and enable them to react in emergency. Therefore, a new measuring concept called "On-site Visualization" ( $O S V$ for short) has been proposed in Japan recently to improve the monitoring of the deformation or the strain of structures during construc$\operatorname{tion}^{3), 4), 5)}$. It aims to measure the displacements of the structures and visualize the measured results in realtime by different colors of light or other signs which can be visually recognized by the onsite workers.

As shown in Fig.2, the $O S V$ method has experienced 3 phases by far. In the first phase of $O S V$, the electric 


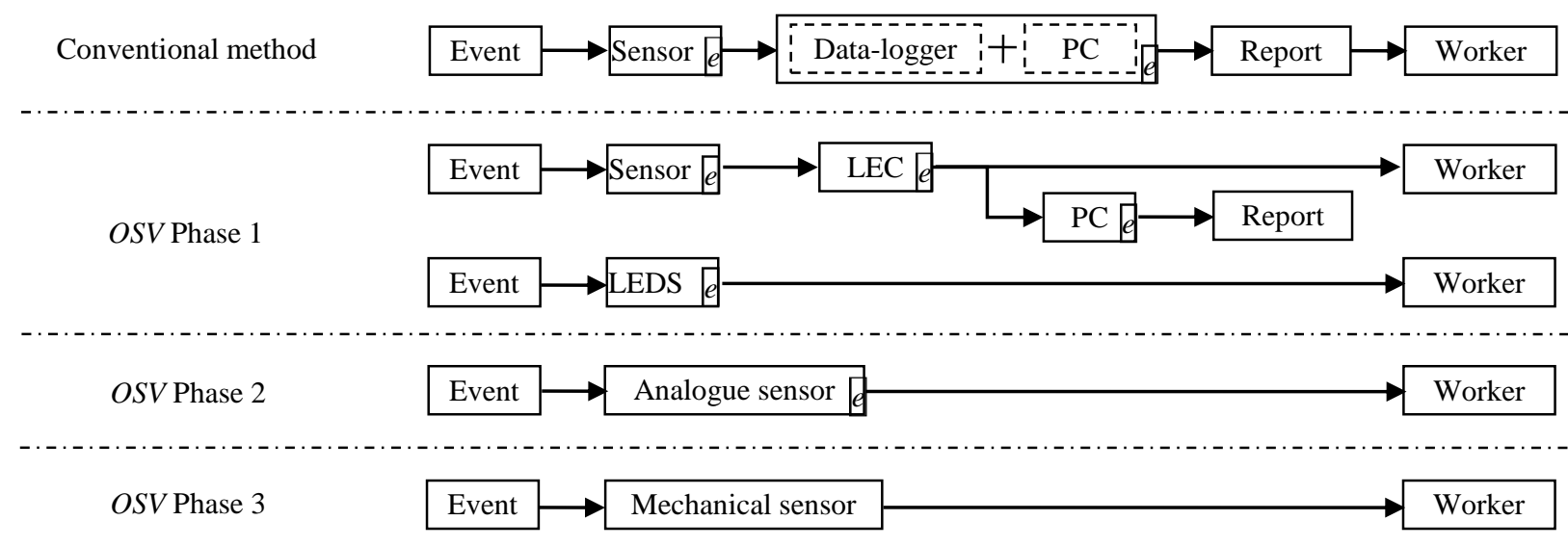

Note: LEC: Light Emitting Converter; LEDS: Light Emitting Deformation Sensor;

$e:$ If a device uses electricity, " $e$ " is shown in the box.

Fig.2 Development of $O S V$ method.

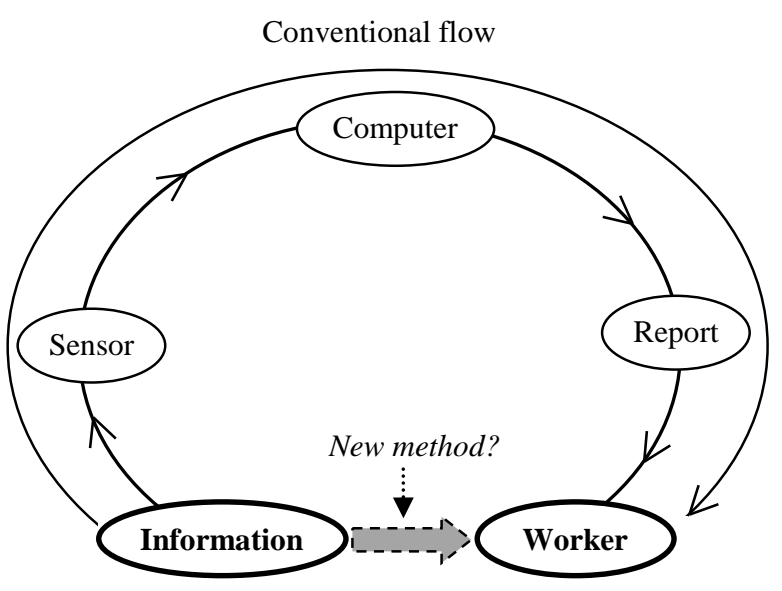

Fig.1 Flow of information distribution in field measurement.

units are utilized to visualize the deformation simultaneously on site. For example, the Light Emitting Converter (LEC) is able to convert the electrical signal of the normal strain gauge into the change of color of light. It is a compact data processor with the function of simultaneous visualization. These devices had been applied in several construction projects and proved to be helpful for the safety management of the construction. However, in the view of cost of measurement, these devices are not exceedingly superior to the conventional ones due to the cost of electric devices in the same order as that of the conventional methods.

In the second phase of $O S V$, the analogue sensors are developed to measure and visualize the deformations in real-time ${ }^{6}$. It makes use of the change of color of emitted light as the analogue signal when the white light passes through different color filters. Take the ground deformation sensor for example. It can visualize the movement of ground by different colors of light from the shift of the filter of different colors that moves together with the ground, using the optical fiber as the propagation medium.

In the third phase of $O S V$, the mechanical methods are introduced to visualize the deformation or the inclination in real-time without using electricity), which is the main work presented in the paper. The cost of measurement is always a limiting factor when choosing a suitable monitoring method during construction. Since the simple mechanical methods use no electric units, the cost could be controlled at a relatively low level. The similar idea was applied in coal mining in South Africa to monitor and visualize the roof displacement of mine openings within or above the bolted height by installing a dual height telltale ${ }^{8)}$. But there is rare trial of such kind of mechanical method in civil engineering in documentation.

In the practice of tunneling, although the monitoring work was undertaken and checked at the limited sections of the tunnel under the contract, collapse accidents still happened during tunneling ${ }^{9), 10)}$. The accident is a complex result of many influence factors, while the Heinrich's Law suggests that if the unsafe acts and the unsafe conditions are taken care of in time, the chance of fatal accidents will be reduced accordingly ${ }^{11)}$. As it is also pointed out that the identification of hazard sources is the primary phase of the risk assessment for preventing accident ${ }^{12)}$, it is recommended to monitor as many states of deformation of the structures and ground as possible because of the uncertainty of geological conditions during tunneling.

The relationship between the rate of unidentified hazard sources and the number of instruments could be simplified as shown in Fig.3. The rate of unidentified hazard sources decreases with increasing instrumentation number during construction, denoted 


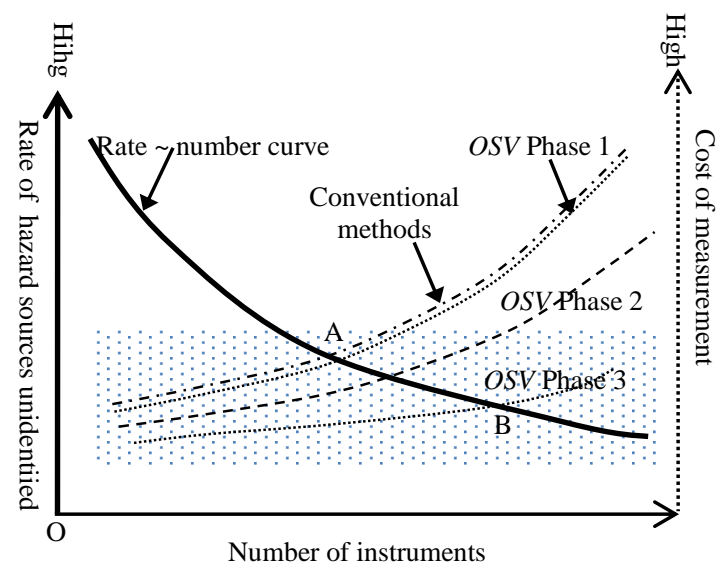

Fig.3 Illustration of rate of hazard sources unidentified and the cost with respect to number of instruments.

as the thick solid line (left Y-axis). Here we assume that the measurement instruments are well set up and can function properly. Meanwhile, the cost related to the measurement goes up correspondingly, represented by the dot-dashed line (right Y-axis). It is not economical and practical to conduct the monitoring work intensively along the tunnel with the conventional instruments in order to obtain a high rate of identified hazard sources. The intersection point A represents a relative equilibrium with respect to the cost and the acceptable rate of identified hazard sources. The cost of the devices in the first phase of $O S V$ is close to the conventional ones due to utilization of electric units. The cost of the devices in the second phase of $O S V$ denoted by the dashed line is less than those in the first phase. The shaded area in the figure represents the preferring instrumentation for an available monitoring plan. The dotted line of mechanical OSV method (Phase 3) is preferable by comparing with the other measurement methods. It is found that a low rate of unidentified hazard source could be achieved at a lower cost at the intersection point $B$ than that of point $\mathrm{A}$.

This paper introduces a mechanical sensor without using electricity in order to monitor the relative displacement between two points by rotation of the needle in real-time. The laboratory tests and the field experiment are presented to verify the feasibility of the method. The field experiment was performed in the Hachinoshiri tunneling construction project in Japan. Finally, some applications of the method to monitor the displacement are discussed briefly.

\section{DESCRIPTION OF THE METHOD}

The mechanical deformation sensor used here is a device which is able to measure the relative displace-

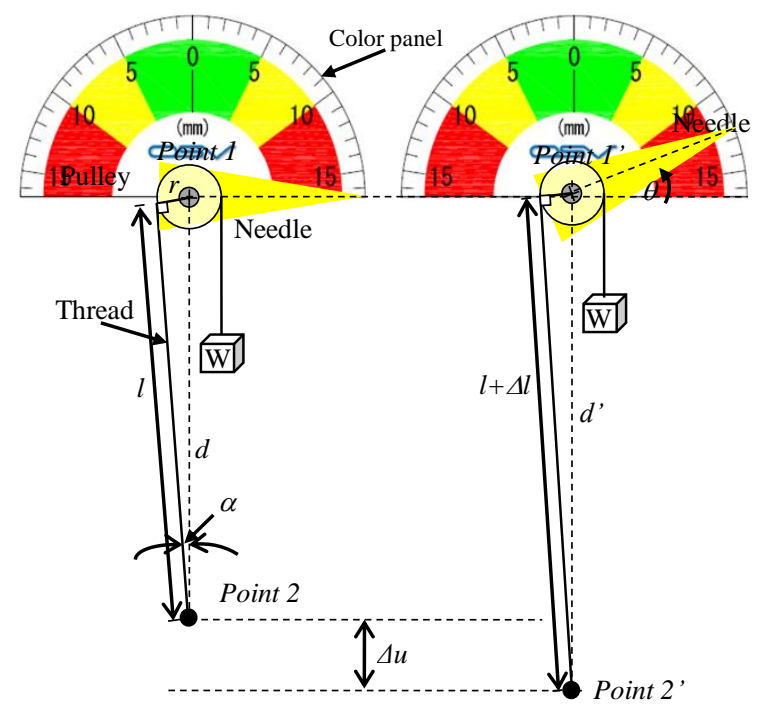

(a) Before

(b) After

Fig.4 Layout of the deformation sensor.

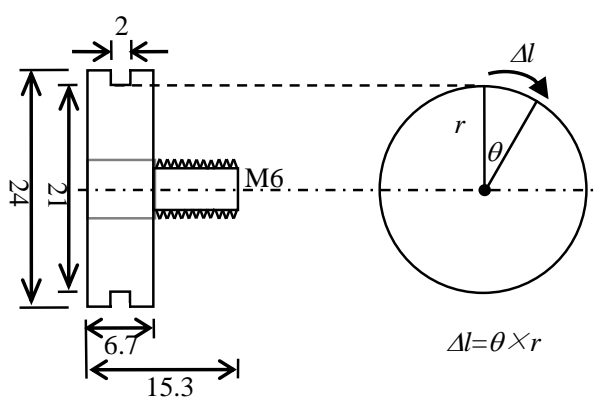

(a)Size of pulley (unit: $\mathrm{mm}$ )

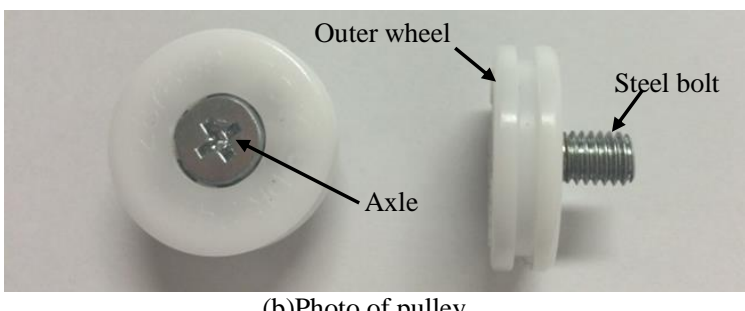

Fig.5 Details of pulley.

ment between two arbitrary points and show the result by the rotation of the indicator simultaneously on site.

As shown in Fig.4, the sensor consists of two main components. The first component is the thread with high stiffness in tension and good flexibility in bend which can mobilize a pulley to rotate when a relative displacement occurs between the two points connected by the thread. The pulley is to translate the linear displacement into the rotation, and its diameter determines the sensitivity of the measurement with respect to the displacement. The details of the pulley are shown in Fig.5. The second component is the indicator, here represented as the needle, which is attached on the side of the pulley for visualization of 


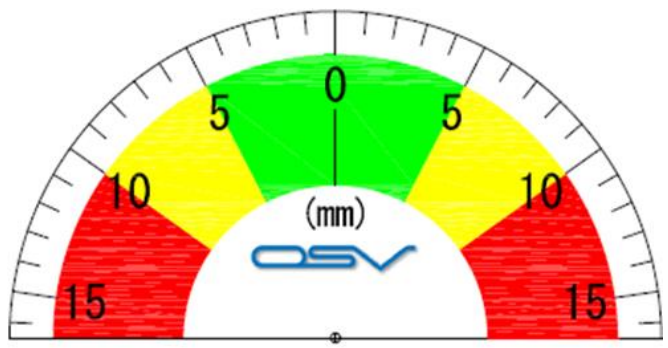

Fig.6 Example of the plastic color board.

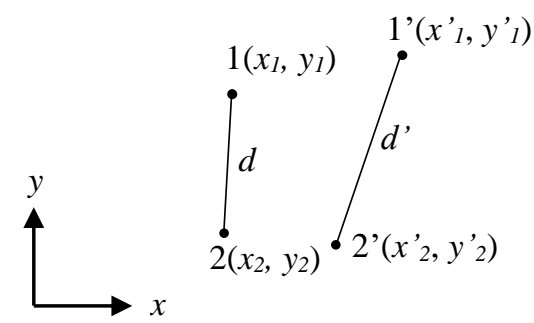

Fig.7 Relative displacement between two points.

measured displacement. The length of the needle (s) is $150 \mathrm{~mm}$.

The tension of the thread rotating around the pulley is provided by the weight or spring. A plastic board within gradation is positioned behind the indicator so that the displacement can be read in quantity (Fig.6). The board is subdivided into colored sectors according to necessary safety levels.

As shown in Fig.7, given two points $1\left(x_{1}, y_{1}\right)$ and $2\left(x_{2}, y_{2}\right)$, The distance $(d)$ between points 1 and 2 can be expressed as:

$$
d=\sqrt{\left(x_{1}-x_{2}\right)^{2}-\left(y_{1}-y_{2}\right)^{2}}
$$

After deforming, the new coordinates of the two points become $1^{\prime}\left(x^{\prime}{ }_{1}, y^{\prime}{ }_{1}\right)$ and $2^{\prime}\left(x^{\prime}{ }_{2}, y_{2}^{\prime}\right)$ respectively. And the distance $\left(d^{\prime}\right)$ between the two points is given by:

$$
d^{\prime}=\sqrt{\left(x_{1}^{\prime}-x_{2}^{\prime}\right)^{2}-\left(y_{1}^{\prime}{ }_{1}-y_{2}^{\prime}{ }_{2}\right)^{2}}
$$

Therefore, the relative displacement $(\Delta u)$ between the two points can be given by:

$$
\Delta u=d^{\prime}-d
$$

Paralleling Line (1'2') with Line(12) by rotating Line(1'2') as shown in Fig.4, the relative distance $(\Delta u)$ will be the same. Whatever state of Line(1'2') is due to the structure deformation, this kind of parallel translation always works. In order to measure the movement of points 1 and 2, the pulley of the sensor is set up at point 1 which can be regarded as the unmovable. Whichever one is chosen as the unmovable point is up to the users. The thread goes around the circumference of the pulley, within one end connected to point 2 and the other end connected to a weight. In Fig.4, point 2 moves along the line parallel

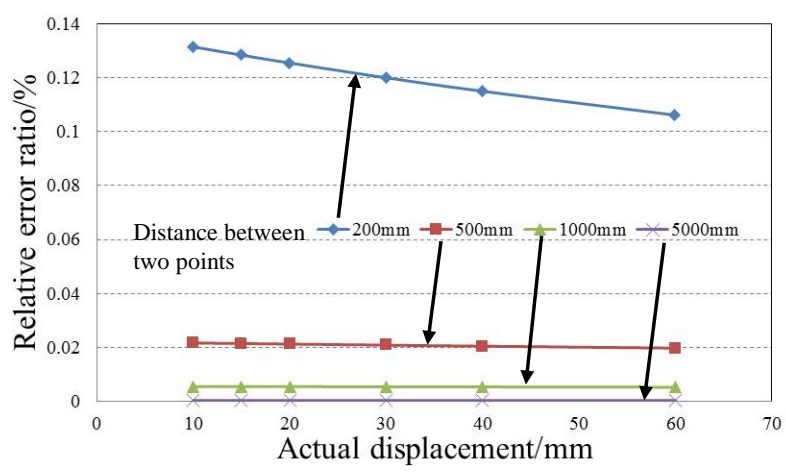

Fig.8 Error analysis.

with Line(12). The relationship between the relative displacement $(\Delta u)$ and the arc length of rotation of pulley $(\Delta l)$ is derived as follows:

$$
\begin{gathered}
l^{2}+r^{2}=d^{2} \\
(l+\Delta l)^{2}+r^{2}=(d+u)^{2}
\end{gathered}
$$

Eliminate $r$ from Equations (4a) and (4b) to obtain a new Equation (4c)

$$
u^{2}+2 d u-\left(\Delta l^{2}+2 \Delta l \cdot l\right)=0
$$

solve for $u$ in Equation (1c)

$$
u=\sqrt{\Delta l^{2}+2 \Delta l \cdot l+d^{2}}-d
$$

since

$$
l=d \cdot \cos \alpha
$$

then

$$
u=\sqrt{\Delta l^{2}+2 \Delta l \cdot d \cdot \cos \alpha+d^{2}}-d
$$

as $\alpha$ gets close to 1 , we will have

$$
\cos \alpha \approx 1
$$

whence

$$
u \approx \sqrt{\Delta l^{2}+2 \Delta l \cdot d+d^{2}}-d
$$

finally

$$
u \approx \Delta l
$$

where, $\Delta u$ is the relative displacement between two points, $d$ is the distance between two points, $r$ is the radius of pulley, $l$ is the length of the tangent line, $\Delta l$ is the arc length of rotation of pulley, $\alpha$ is the intersection angle between the tangent line of thread and the line that goes through points 1 and 2 .

The results of theoretical error analysis with respect to different distance $(d)$ between two points are shown in Fig. 8. The relative error ratio is expressed as Formula (5):

$$
\text { Relative error ratio }=\frac{\Delta l-\Delta u}{\Delta u} \times 100 \%
$$

where, " $\Delta u$ " represents the actual displacement between two points, " $\Delta l$ " represents the measured displacement by the mechanical sensor in Fig.4.

It can be figured out that the longer the distance between two points is ( $\alpha$ close to 0 ), the more accurate the measured result is. Even in case of the distance of $200 \mathrm{~mm}$ between two points, the relative error ratio is less than $0.14 \%$. In addition, the relative error ratio decreases as the relative displacement between two points increases. All the approximate relationship between the actual displacement and the 
measured value between two points is based on the assumption of infinitesimal of angle $\alpha$. Therefore, the measured displacement by the sensor can be accepted as the actual displacement between two points.

The deformation of structure is measured and visualizd by the rotation of the indicator (needle). From experience, the movement $(\omega)$ of tip of the indicator as small as $2 \mathrm{~mm}$ can be well identified by eyesight. The relationship of measured displacement $(\Delta u)$, radius of pulley $(r)$, rotation angle $(\theta), \omega$ and lengh of needle $(s)$ can be expressed as:

$$
\Delta u=r \times \theta=r \times(\omega / s)
$$

It shows that smaller " $r$ ", larger "s" can result in higher measurement accuracy. In this research, we have $r=10.5 \mathrm{~mm}, \omega=2 \mathrm{~mm}$ and $\mathrm{s}=150 \mathrm{~mm}$, so, $\Delta u$ $=0.14 \mathrm{~mm}$. It means that a relative displacement of $0.14 \mathrm{~mm}$ can be visualized by this method theoretically.

As shown in Fig.7, it should be noted that, it is possible structure deformation happens while the relative displacement $(\Delta u)$ between the two points remains zero. In this case, the deformaton cannot be visualizd by this sensor.

\section{LABORATORY TEST}

\section{(1) Material of components}

The sensor is made up of the components which can be found easily in the market. The reliability of the sensor depends largely on the property of the material of its components. A plastic pulley with a diameter of $21 \mathrm{~mm}$ (Fig.5) is adopted in this research. Its axle is made of steel. And the outer wheel of the pulley is made of polyoxymethylene which is an engineering material used in precision parts requiring high stiffness and excellent dimensional stability. The property of polyoxymethylene is shown in Table 1. It could be thought the influence of deformation of pulley would be negligible during the experiment in this research. The very important component is the thread which connects the two measuring points. The thread requires very high stiffness that ensures a complete displacement translation between two points.

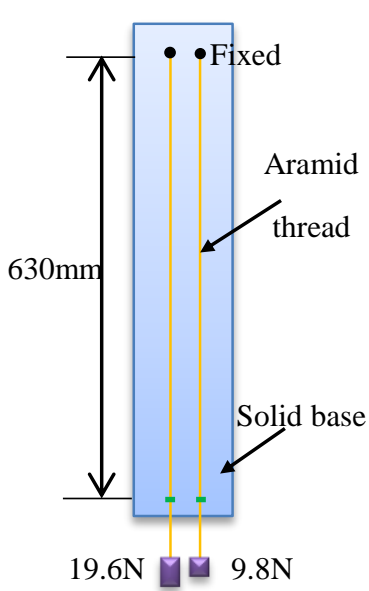

(a)Sketch of the test

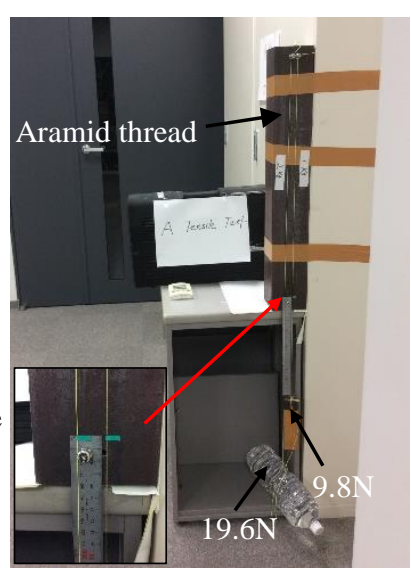

(b)Photo of the test
Fig.9 Layout of the tensile test in the laboratory.

Table 1 Property of polyoxymethylene. (Source: http:// www.matbase.com)

\begin{tabular}{|cccc|}
\hline Parameters & $\begin{array}{c}\text { Density } \\
\left(\mathrm{g} / \mathrm{cm}^{3}\right)\end{array}$ & $\begin{array}{c}\text { Compressive } \\
\text { strength } \\
(\mathrm{MPa})\end{array}$ & $\begin{array}{c}\text { Young's } \\
\text { modulus } \\
(\mathrm{MPa})\end{array}$ \\
\hline Values & 1.420 & 31 & 3500 \\
\hline
\end{tabular}

The aramid fiber is chosen as the thread. As shown in Table 2, the aramid thread is the product which is light weight, has high strength, high modulus, and good chemical and thermal stability.

\section{(2) A tensile test}

The laboratory test is performed to determine the creep feature and the tensile ratio of the aramid thread under different weight loads $(9.8 \mathrm{~N}$ and $19.6 \mathrm{~N})$ as shown in Fig. 9. The tensile load is applied to the aramid thread at one end while the other end is fixed from a solid point at the steel block. The elongation of the aramid thread is recorded against the applied load at an interval of about 24 hours. This experiment was terminated in five days when there was no apparent change in length of the thread any more.

As shown in Fig. 10, the aramid threads exhibit different extension characteristics with respect to the applied loads during the first three days. After that,

Table 2 Property of the aramid thread used in the test.

(Source: http://www.td-net.co.jp)

\begin{tabular}{|cccccc|}
\hline \multirow{2}{*}{ Parameters } & Diameter & Density & Elastic modulus & Extensibility & $\begin{array}{c}\text { Coefficient of } \\
\text { thermal expansion }\left(<150{ }^{\circ} \mathrm{C}\right)\end{array}$ \\
\cline { 2 - 6 } & $\mathrm{mm}$ & $\mathrm{g} / \mathrm{cm}^{3}$ & $\mathrm{MPa}$ & $\%$ & $\mathrm{~cm} / \mathrm{cm} /{ }^{\circ} \mathrm{C}$ \\
\hline Values & 0.69 & 1.44 & 70500 & 4.8 & $4.0 \times 10^{-6}$ \\
\hline
\end{tabular}


Table 4 Information of critical friction tests.

\begin{tabular}{|ccc|}
\hline Parameters & Case1 & Case2 \\
\hline Weight $(\mathrm{N})$ & 9.8 & 19.6 \\
\cline { 2 - 3 } Temperature $\left({ }^{\circ} \mathrm{C}\right)$ & \multicolumn{2}{c|}{$23.6 \sim 24.3$} \\
Moisture (\%) & \multicolumn{2}{c|}{$46 \sim 65$} \\
Period of time (day) & \multicolumn{2}{c|}{5} \\
Length (mm) & 630 & 630 \\
Stretch (mm) & 0.2 & 0.5 \\
Extensibility & $0.048 \%$ & $0.079 \%$ \\
\hline
\end{tabular}

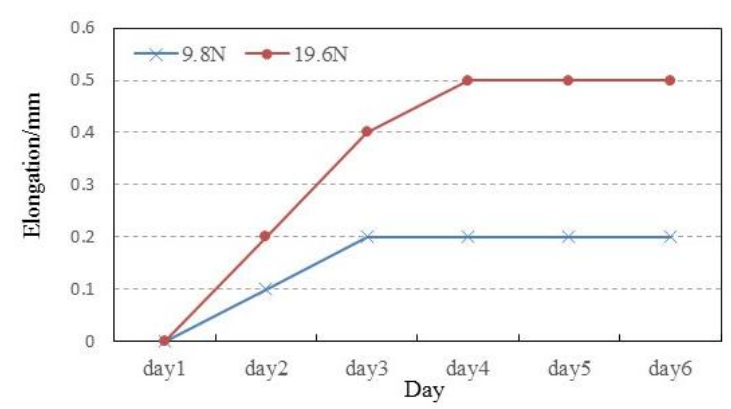

Fig.10 Elongation of the aramid thread against time.

the elongation of the thread is too small to be sensed, which allows us to deem that the aramid thread is in a stable state. Table 3 shows the results of the tensile test. The extensibility of the aramid thread increases as the load increases. The maximum extensibility is $0.079 \%$ under the load of $19.6 \mathrm{~N}$ while it is $0.048 \%$ under the load of $9.8 \mathrm{~N}$.

In case of monitoring of concrete crack, if two points within a distance of less than $500 \mathrm{~mm}$ are connected by the aramid thread under the load of less than $4.9 \mathrm{~N}$, the elongation of the thread would be less than $0.15 \mathrm{~mm}$ (calculation based on linear relationship with the load of $9.8 \mathrm{~N}$ ), which is hard to be identified by human eye. For the measurement of conver

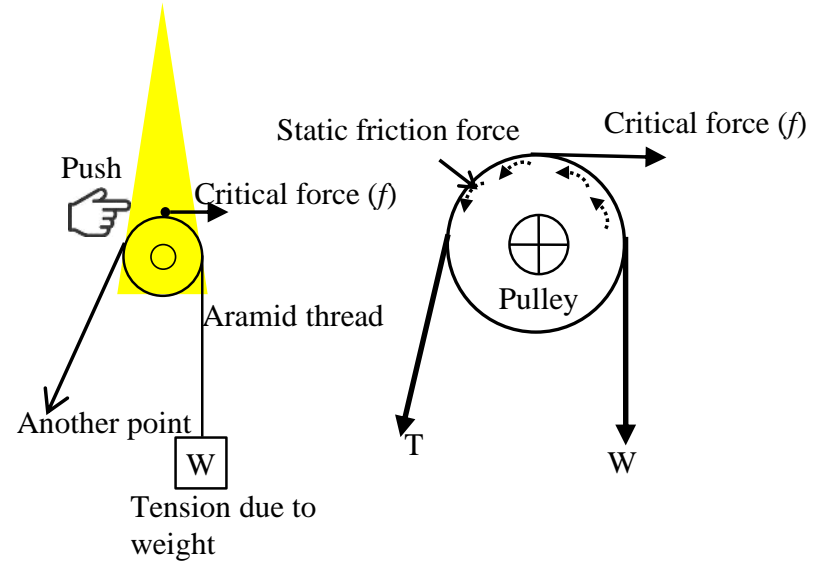

(a)Influenced by external force (b)Details of forces

Fig.11 Critical force between pulley and thread.

\begin{tabular}{|cccc|}
\hline Parameters & Case4 & Case5 & Case6 \\
\hline Weight $(\mathrm{N})$ & 4.9 & 9.8 & 19.6 \\
\cline { 2 - 3 } Temperature $\left({ }^{\circ} \mathrm{C}\right)$ & \multicolumn{3}{|c}{$19.6 \sim 22.6$} \\
Moisture $(\%)$ & $33 \sim 46$ \\
\hline
\end{tabular}

gence displacement in a tunnel, the length of the thread is so large (e.g., $8,000 \mathrm{~mm}$ ) that the elongation of aramid thread due to applied weight should be taken account of in the error analysis.

\section{(3) Critical force tests}

In order to minimize the extensibility effect of the aramid thread, it is better to keep its tension smaller. On the other hand, at tunnel construction site, some unexpected contact with the needle or thread may happen to mobilize the pulley to rotate with a slip relative to the thread, making the measured results incorrect. Therefore, the critical force is proposed to determine the proper load, which ensures there is no sliding between the thread and the pulley. The critical force is defined as the force equal to the maximum static frictional force around the circumference of the pulley as shown in Fig.11. In another word, if the unintended external force is less than the critical force, the rotation of pulley mobilized by the thread without sliding can be ensured.

A critical force test is carried out under 3 different loads (4.9N, 9.8N and 19.6N) as shown in Fig.12 and Table 4. It is similar to the tensile test. The sensor is fixed at a solid point on the wall that does not move. The aramid thread is set up along the groove of the pulley, within one end fixed from another solid point on the wall. The other end of the thread is loaded by the designated weight. The result of relationship between applied load and critical force is shown in

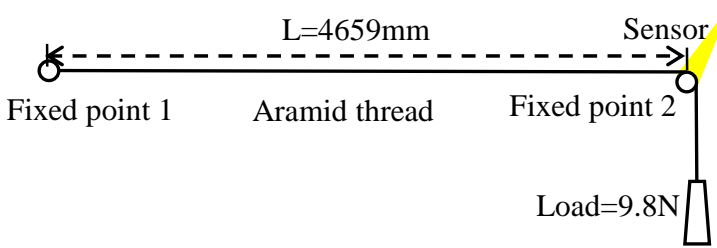

(a)Layout of experiment

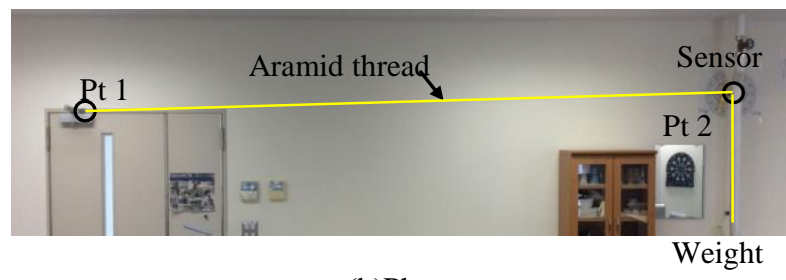

(b)Photo

Fig.12 The critical force test in the laboratory (Case 5). 


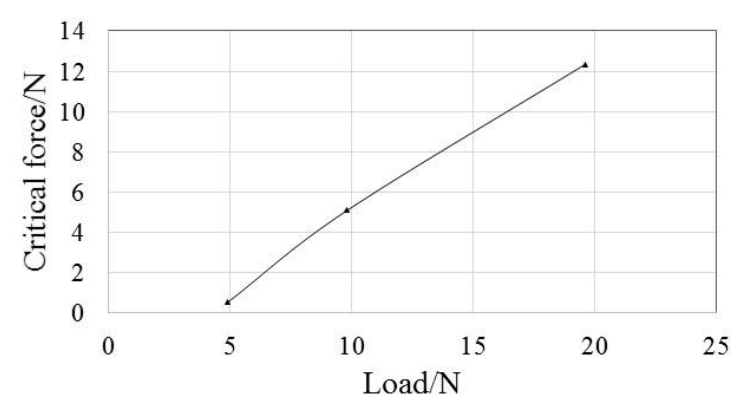

Fig.13 Relationship between critical force and load.

Fig.13. It can be found that the critical force increases in accordance with the increasing weight load. For example, in this experiment, in the case of the load of $4.9 \mathrm{~N}$, an equivalent external force of less than $0.5 \mathrm{~N}$ would not affect the results. Based on this test, a proper weight ought to be decided to provide suitable tension of the thread, of course, not having effect on the deformation of the structure, in the field measurement.

\section{(4) Analysis of other influence factors}

There are some other factors such as the temperature, the wind, the sunlight and the moisture to be in considerations which could influence the measured results of relative displacement during monitoring. The aramid thread in this research has a very small coefficient of thermal expansion under $150^{\circ} \mathrm{C}$ as shown in Table 2, which allows that the effect of temperature change in the tunnel can be negligible. However, this kind of aramid thread is not recommended to be exposed directly in the sunlight or in the environment with high moisture content, where the strength of the thread decreases over time. A further experiment on the influence due to the moisture and sunlight should be carried out in the next study. Nevertheless, by taking some proper protection measures, the sensor is possible to provide a reliable result of the displacement to meet the requirement of monitoring.

\section{FIELD EXPERIMENT}

\section{(1) Project overview}

The Hachinoshiri Tunnel is located in the Pref. Yamanashi which is an important part of the Chubu Odan Expressway in Japan. As shown in Fig.14, the tunnel project with the length of $2469 \mathrm{~m}$ and the typical excavated cross section area of $82 \mathrm{~m}^{2}$ was conducted by New Austrian Tunneling Method (NATM) through various geologies, including the weak ground such as the mudstone. In the weak stratum, some new excavation approaches such as the curved tunnel face and early invert installing methods were adopted to improve the tunneling stability during excavation $^{11)}$. However, when the tunnel was excavated through the mudstone stratum, excessive deformations of the linings of the tunnel were encountered with, which made the construction delayed for several months. The results of convergence measurement by Total Station showed a relative displacement in horizontal line increased to $15 \mathrm{~mm}$ in 24 hours after the prism was set up at one measuring section, and 200 days later its maximum value became $674 \mathrm{~mm}$. The mudstone is so weak that its strength ratio (uniaxial compression strength /weight of overburden) is less than 1.1 (Table 5). The cracks of the shotcrete could be often seen physically at the sidewall section along the finished tunnel (Fig.15). Although the

Table 5 Geological parameter of the mudstone.

\begin{tabular}{|lccc|}
\hline \multirow{2}{*}{ Rock type } & $\begin{array}{c}\text { Unit } \\
\text { weight }\end{array}$ & Strength ratio & Uniaxial strength \\
\cline { 2 - 4 } & $\mathrm{KN} / \mathrm{m}^{3}$ & - & $\times 10^{6} \mathrm{~N} / \mathrm{m}^{2}$ \\
\hline Mudstone & 21.6 & $0.5 \sim 1.1$ & 0.26 \\
\hline
\end{tabular}

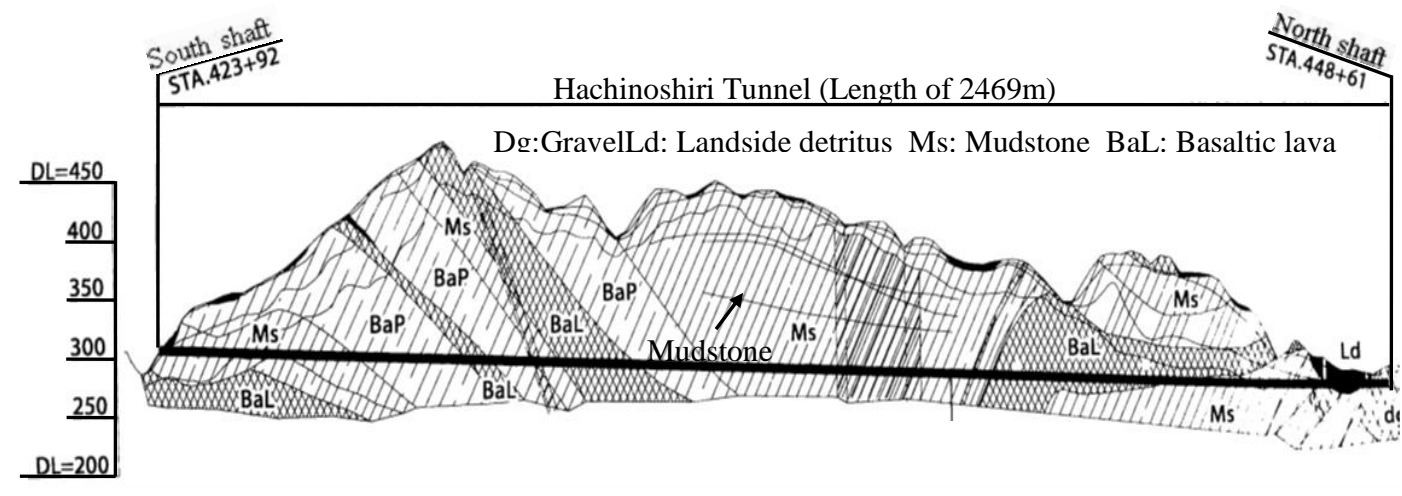

Fig.14 Geological profile of Hachinoshiri Tunnel. 


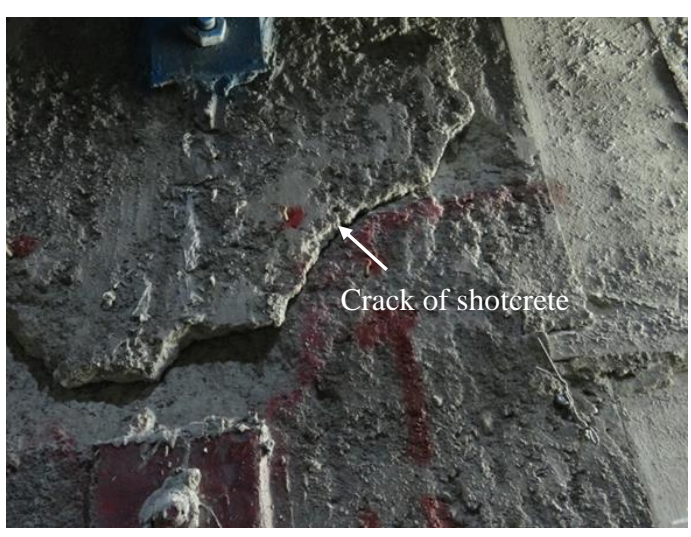

Fig.15 Cracking of the shotcrete.

measurement of deformation had been carried out by Total Station every10m along the tunnel (Fig.16), it was necessary to enhance the monitoring of tunnel during excavation, especially for the deformation cracks of shotcrete associated likely with the interaction of tunnel and weak ground, in the intervals where not monitored before.

\section{(2) Monitoring instrumentation}

The deformation sensors were employed to monitor the tunnel where the conventional measurements were not carried out in the original measurement plan. The measuring points were determined by the veteran engineers. There are no specific rules to decide the interval of the sensors or the number of the sensors. The deformation sensors were set up as early as possible when the state of structure needed to be under additional monitoring. Moreover, the sensors should be set up in avoidance of the touch with the heavy machinery in the tunnel. The monitoring of tunnel structure using the deformation sensors is clas sified into two categories as follows:

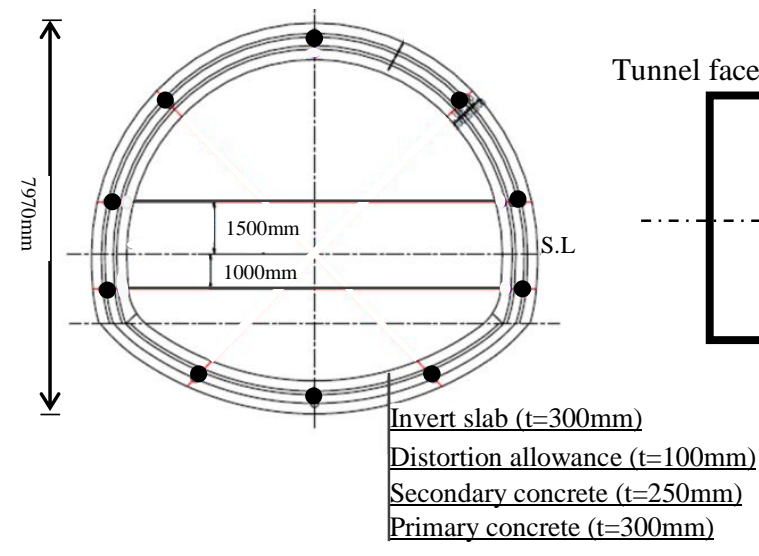

(a)Measured point in the sectional view of tunnel (CC')
(b)Measured points by Total Station in longitudinal direction

Fig.16 Conventional measurement of tunnel by Total Station (Sectional).

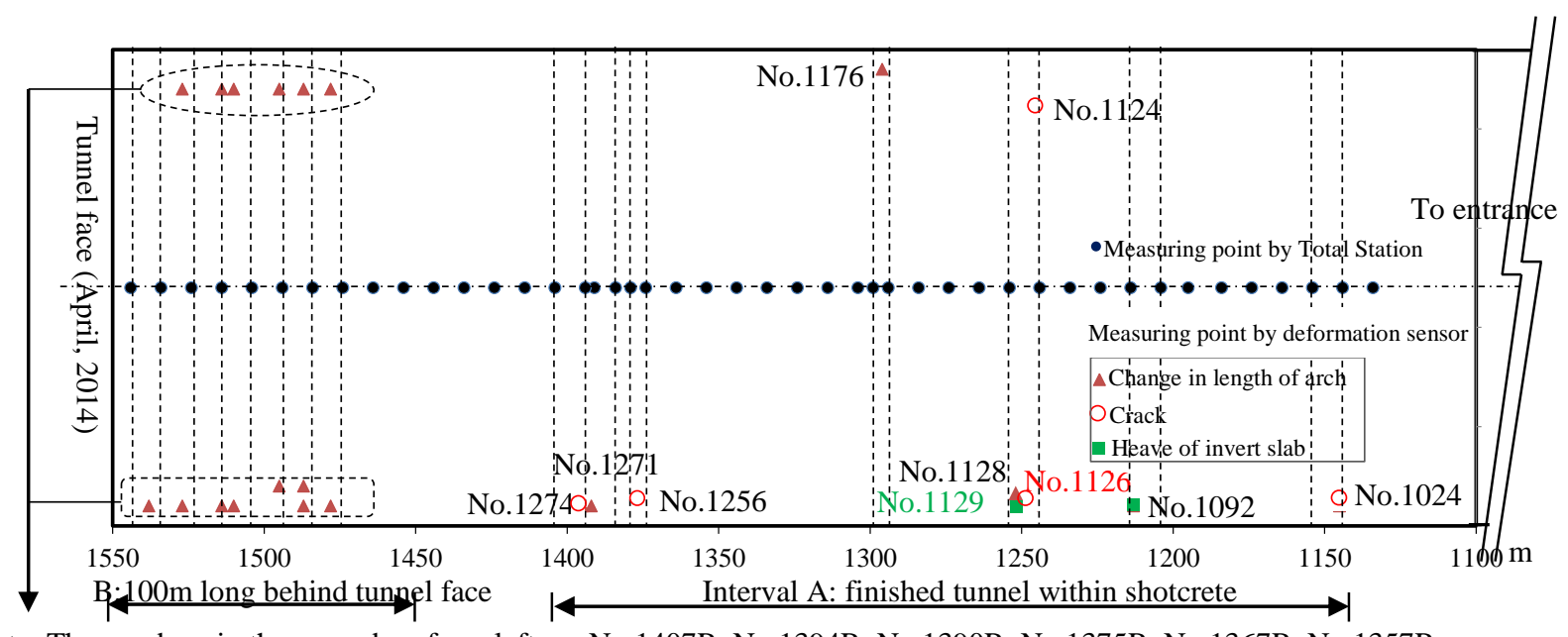

Note: The numbers in the upper box from left are No.1407R, No.1394R, No.1390R, No.1375R, No.1367R, No.1357R

The numbers in the lower box from left are No.1418, No.1407L, No.1394L, No.1375L, No.1367L, No.1367W, No.1357L

Fig.17 Measuring points by deformation sensor and Total Station respectively along the tunnel (plane view). 


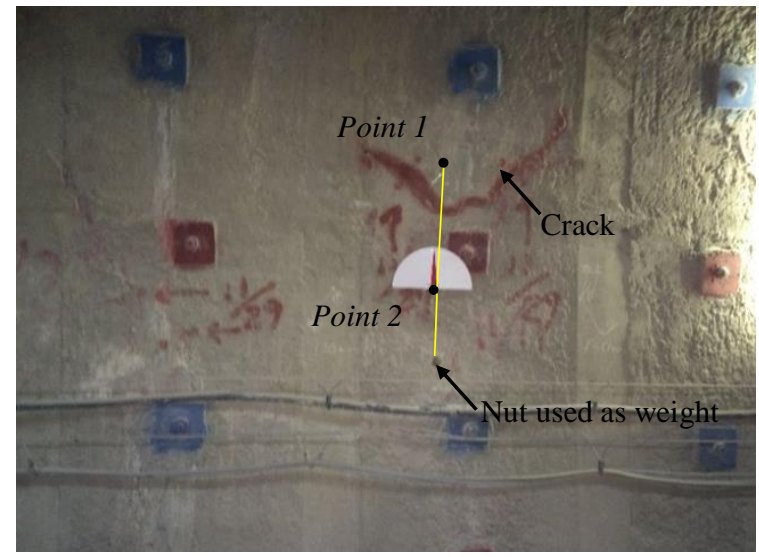

Fig.18 Crack monitoring (No.1124).

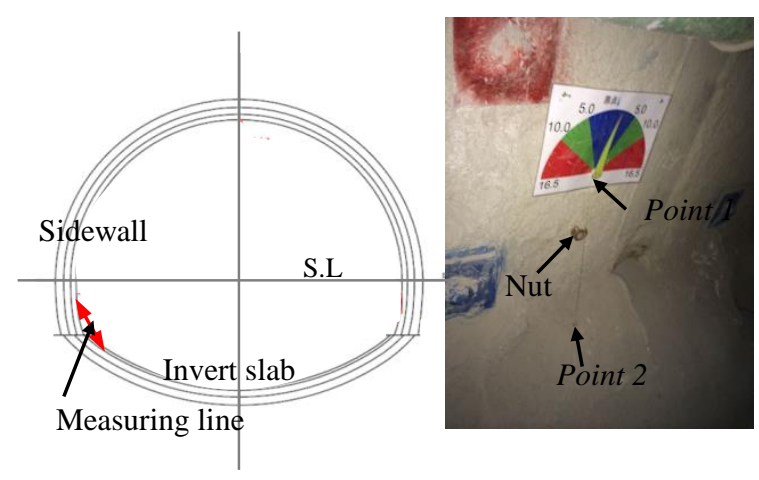

Fig.19 Displacement between the invert and the sidewall (No.1129).

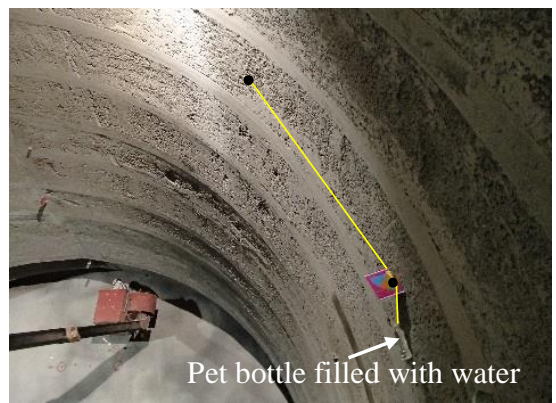

Fig.20 Monitoring of the change in length of the arch section (No.1375R)

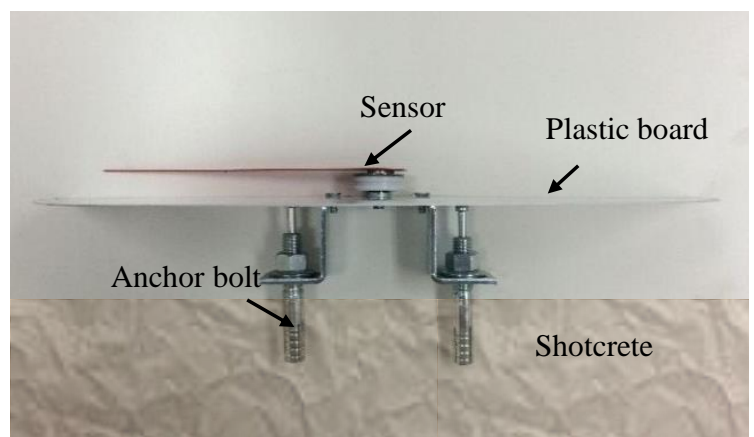

Fig.21 Example of installation of deformation sensor.

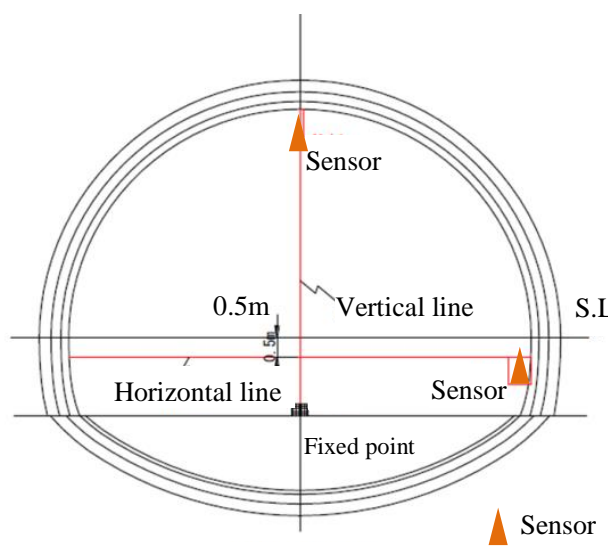

Fig. 22 Convergence monitoring according to vertical and horizontal displacement ( $1 \mathrm{~m}$ behind tunnel face)

\section{a) Routine monitoring}

As shown in Fig.17, although the tunnel face had passed away from interval $A$, some deformations of tunnel structure were found still ongoing. In order to investigate the state of tunnel structure, the cracks of the lining were monitored by the deformation sensor (Fig.18). And the deformations between the invert and the sidewall of the tunnel were also measured (Fig.19).

At interval $B$ with the length of $100 \mathrm{~m}$ behind the tunnel face, the changes in length of the arch section were monitored in real-time by the deformation sensors as show in Fig.20, so that the instant deformation after tunneling could be known as early as possible.

Fig.21 shows the details of the installation of deformation sensor on the surface of shotcrete. The pulley with the indicator is fixed at the shotcrete by the bolts. As shown in Fig.18, the pulley is set up at point 2. The aramid thread goes along the groove of the pulley, with one end fixed at point 1 and another end fixed by a steel nut (about $0.98 \mathrm{~N}$ ) or $500 \mathrm{ml}$ pet bottle (about $4.9 \mathrm{~N}$ in Fig.20). Therefore, the change in crack width can be monitored by this kind of method.

\section{b) Monitoring during break}

There was a one-week break of the excavation during the New Year Festival. It was of importance to know the deformation of the tunnel near the tunnel face before the new excavation continued. Therefore, the convergence of the tunnel $1 \mathrm{~m}$ away from the tunnel face was monitored by measuring the vertical and horizontal displacement respectively, which was not usually done during excavation as shown in Fig.22.

\section{(3) Result analysis}

\section{a) Routine monitoring}

Fig.23 shows some representative records of the relative displacements measured by the mechanical sensors, including the deformation of cracks, the rel- 
ative displacement between the sidewall and the invert slab (heaving), and the change in length of arch section of tunnel. Because the details of most measuring points (for example the distance between two points, weight of each nut) were not recorded clearly during the monitoring, it is difficult to modify every value of the relative displacement due to the elongation of the aramid thread. Although the raw data are used in the paragraph, the trend of the changes of displacements would not be affected. It shows that the deformations of tunnel developed rapidly as the monitoring started. About two months later, the displacements became almost unchanged, which indicated the tunnel was in a stable condition.

Fig.24 shows a comparison between the displacements measured by Total Station and the mechanical deformation sensor ${ }^{12)}$. The heave of the invert slab was monitored by the mechanical sensor (No.1092). The convergence measurement of the tunnel by Total Station was conducted at the cross section $1 \mathrm{~m}$ away from the mechanical sensor (No.1092). Although the measuring objects were different, the displacements measured by these two methods show the same trend, which could present an overall image of the deformation process of the tunnel during construction.

Thus, it is very important to monitor the deformation of the lining during the initial stage of the construction when the deformations develop very rapidly. If an excessive displacement is detected as early as possible, the risk of the tunneling shall be reduced by taking proper countermeasures.

\section{b) Monitoring during break}

For the monitoring during the New Year Festival, the rotation of the needle can be well observed with

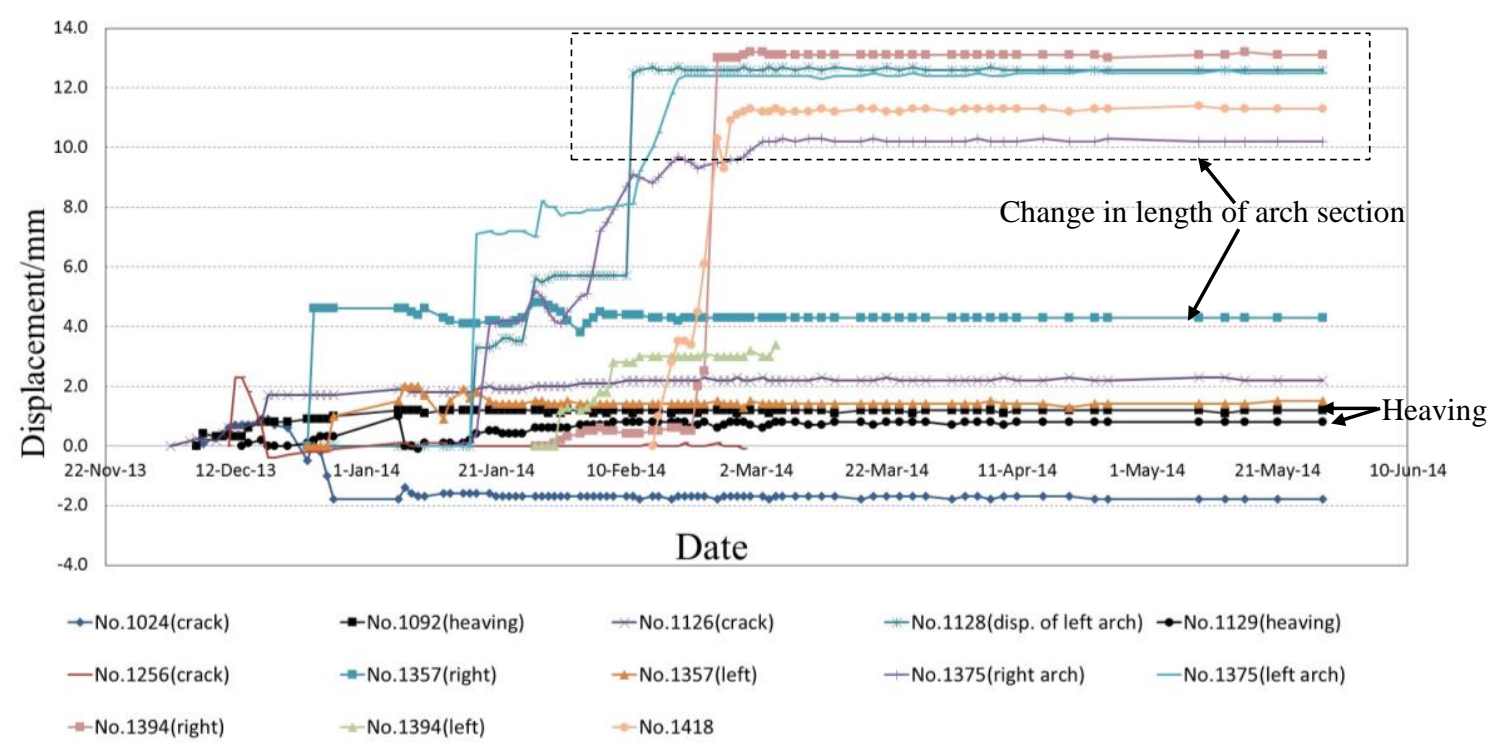

Fig.23 Results of the displacement measured by the mechanical sensors.

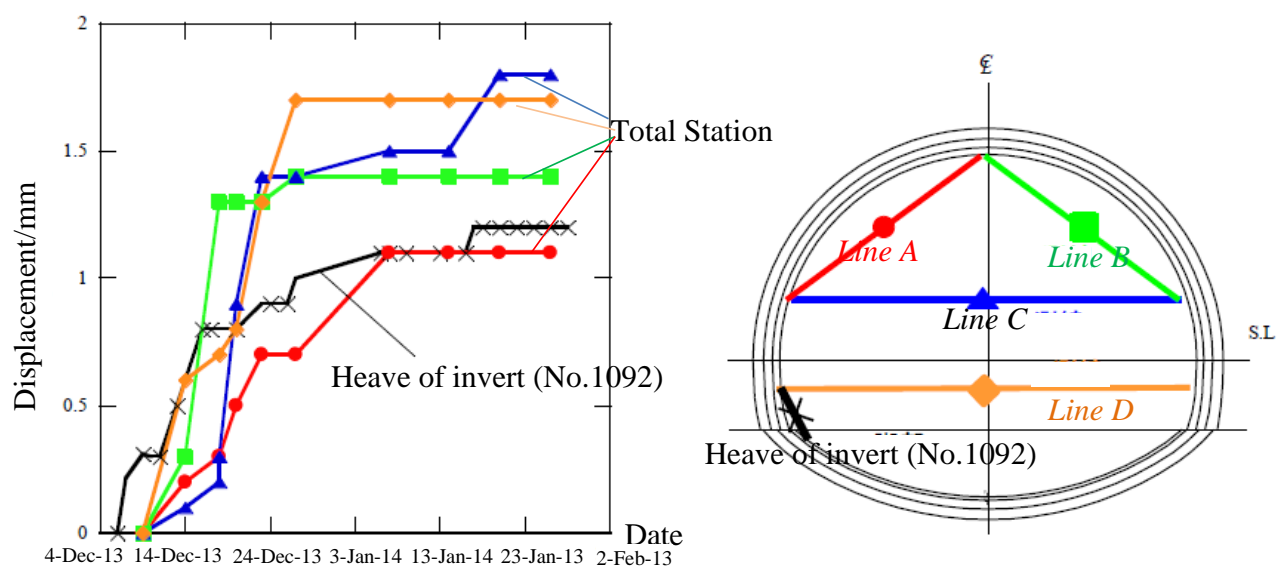

Fig.24 Comparison between the displacements measured by Total Station (TD1214) and mechanical deformation sensor (No.1092). 


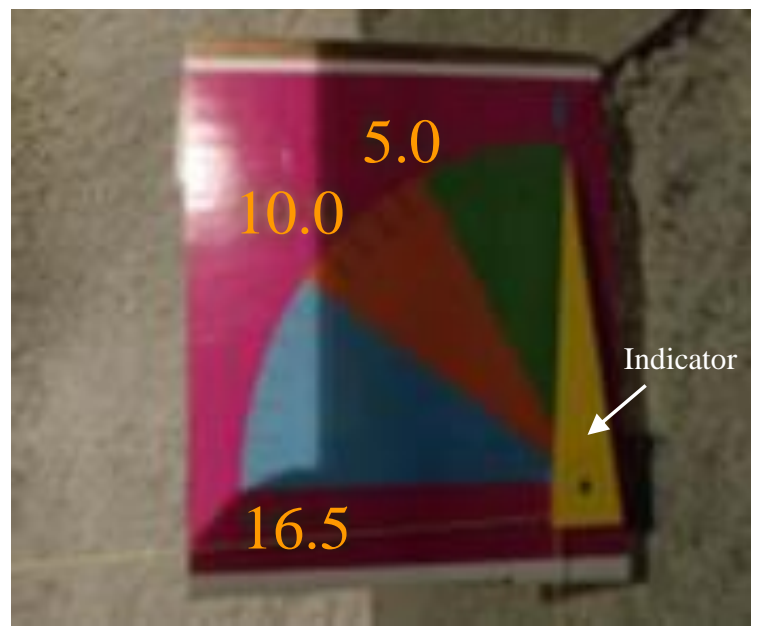

Dec. $28^{\text {th }}, 2013$

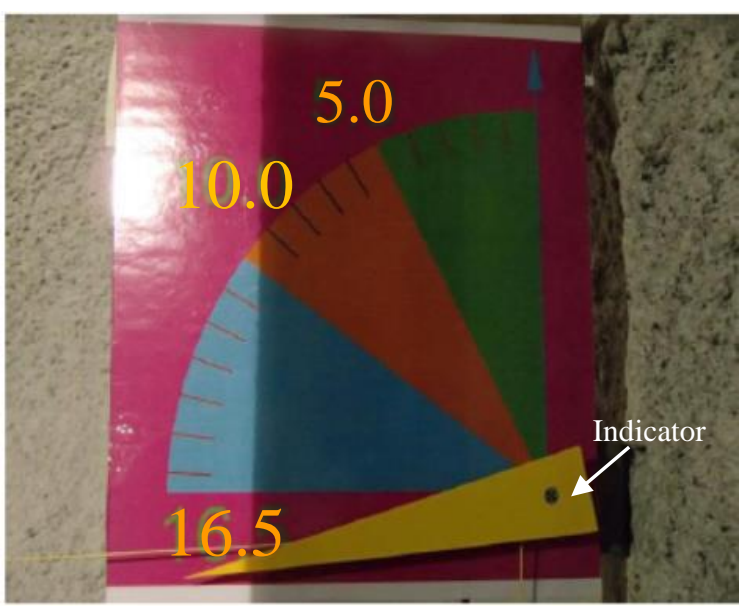

Jan. $6^{\text {th }}, 2014$

Fig.25 Rotation of the indicator visualizing change of the horizontal displacement (Unit: $\mathrm{mm}$ ).

Table 6 Results of convergence measurement.

\begin{tabular}{|ccccc|}
\hline Date & \multicolumn{2}{c}{ Vertical $(\mathrm{mm})$} & \multicolumn{2}{c|}{ Horizontal $(\mathrm{mm})$} \\
\hline $28^{\text {th }}$ Dec., & \multicolumn{2}{c}{0} & \multicolumn{2}{c|}{0} \\
2013 & & & & \\
$6^{\text {th }}$ Jan., & Measured & Modified & Measured & Modified \\
2014 & 12.1 & 9.7 & 18.7 & 14.9 \\
\hline
\end{tabular}

the naked eyes as shown in Fig.25. Therefore, the convergence displacement by which the stability of the tunnel is evaluated is able to be easily obtained.

Table 6 presents the results of displacement measurement of convergence. The measured displacements are modified considering the elongation of aramid thread. Take the measurement of horizontal line for example, its length is $12.5 \mathrm{~m}$, the weight of the load (pet bottle filled with water) is $4.9 \mathrm{~N}$, the extensibility is $0.031 \%$ (simplified linear relationship based on Table 3), so the elongation of the aramid thread would be $3.8 \mathrm{~mm}(12.5 \times 0.031 \% \times 1000)$, thus, the revised displacement of horizontal line is $14.9 \mathrm{~mm}$ (18.7-3.8). Based on the visualization of deformation results, the engineers and workers were able to evaluate the safety level easily as early as possible during tunneling construction.

\section{DISCUSSIONS}

The cost and result presentation are two representative issues for deformation monitoring during construction, which have an effect on the safety management eventually. The concept of "On-site Visualization" is proposed in response to provide new monitoring technologies for deformation measurement, especially for the safety of the onsite workers.

For the measurement by Total Station during tunneling, the deformation of the tunnel is usually measured only at selected sections and there is a delay to report the results of measurement. In order to improve the quality of monitoring, it is better to employ easy-to-use sensors as an auxiliary means for monitoring. The mechanical method without using electric device is expected to measure and visualize the relative displacement between two points in real-time at an acceptable cost, which makes it possible to monitor displacement at many locations during tunneling. Furthermore, the structure of the sensor is very simple so that even the onsite workers can easily repair and modify the sensor when it is broken. Thirdly, since the deformation sensor is easy to be installed on site and works immediately, an earlier acquisition of the deformations of tunnel during construction is able to be attained. If an unusual displacement is specified early by the mechanical sensor, a precision measurement of the structure within Total Station can be carried out in response.

The aramid thread is used in this research as the connection between two points. Though it has very high elastic Young's modulus, the laboratory experiment proves there exists a little elongation of the thread over time. But the elongation of the thread can be controlled at very low level by choosing a proper light weight. We are trying to find out new material of the thread in the next research. Since the visual data confirmation is usually done near the sensors, if 
necessary, other additional attachment such as the audio device may be added to give out warning.

The original intention of the use of the mechanical deformation sensor is to find the deformations of the structure as early as possible and at as many locations as possible. It can be implemented at the area of secondary importance where large deformations might emerge, or progressive deformation of the cracks in shotcrete. As shown in Fig.22, the increase of deformation of cracks can be well visualized by this sensor, and the engineer at the construction site can judge whether it necessary to take action to enhance the supporting strength of the tunnel synthetically. It can also work in the area of importance, which is visually blocked by the airduct or construction machine and Total Station cannot be used.

The examples presented in this paper have proved that the proposed method not only fulfills that purpose, but also can be extended to monitor the displacement of much smaller or larger order just by changing the radius of pulley. Therefore, in practice, not only can the structures during construction be monitored by this deformation sensor, but the old tunnel can adopt it for monitoring of deformation during service time. This method is also applicable in monitoring the movement of the slope, the foundation pit excavation and so on.

\section{CONCLUSIONS}

The concept of "On-site Visualization" method for construction monitoring is introduced briefly in this paper. A mechanical method based on this concept is proposed to monitor the relative displacement between two points, such as convergence displacement of tunnel and the cracks of linings. The laboratory and field experiments were carried out to verify the feasibility of this method. The field measurement provides the realistic quantitative and visible evaluation of the onsite performance of the tunnel structure during excavation. Therefore, it is possible to improve the safety management of NATM tunneling by using this mechanical method.

ACKNOWLEDGMENT: The work was partially supported by the Ministry of Land, Infrastructure, Transport and Tourism, Kinki Regional Development Bureau, Kinan Office. The authors also wish to thank Central Nippon Expressway Company Limited for the cooperation for the field experiment.

\section{REFERENCES}

1) Villy A. Kontogianni, Stathis C. Stiros : Induced deformation during tunnel excavation: Evidence from geodetic monitoring, Engineering Geology, Vol. 79, Issues 1-2, pp. 115-126, 2005.

2) Sakamoto, Y., Kondou, K., Oda, K., Uchida, O. and Ono, T. : A simple noncontact method for deflection calculation using the digital camera imaging, Proc. of $65^{\text {th }}$ Japan Society of Civil Engineers Symposium, CD-ROM, 2012. (In Japanese)

3) Akutagawa, S., Takano; K. and Takenaka, T. : Development of a new device to translate relative deformation into color of light and its application, General Convention for Japan Society for Civil Engineers, Hiroshima, CD-ROM 3-01., 2007. (in Japanese)

4) Akutagawa, S. and Mori, S. : Development of new deformation sensors for monitoring of infrastructures, Proc. of the EIT-JSCE Joint Seminar on Rock Engineering, Bangkok, pp.192-195, 2008.

5) Akutagawa, S. : On Site Visualization as a new paradigm for field measurement in rock engineering, Proc. of the $6^{\text {th }}$ Asian Rock Mechanics Symposium, New Delhi, pp.34-45, 2010b.

6) Akutagawa, S., Zhang, H., Terashima, M. and Tsujimura, K. : Measurement and real-time visual presentation of the ground deformation ahead of mountain tunnel face using optical fibers, Proc. of Sinorock Symposium for the $3^{\text {rd }}$ International Society for Rock Mechanics, Shanghai, pp.759762, 2013.

7) Akutagawa, S., Zhang, H., Terashima, M. and Tsujimura, K. : Simple mechanical methods for monitoring and datavisualization during NATM tunnel construction, Proc. of $42^{\text {nd }}$ Symposium for Rock Mechanics, Tokyo, CD-ROM, 2014.

8) Altounyan, P. Taljaard, D. : Developments in controlling the roof in South African coal mines -a smarter approach, The Journal of The South African Institute of Mining and Metallurgy, pp.33-40, 2001.

9) Health and Safety Executive: The collapse of a NATM tunnels at Heathrow airport - a report of the investigation by the Health and Safety Executive, HSE books, Sudbury Suffolk, ISBN 0717617920, 2000.

10) Kitahara, S. Ohta, T., Kawagoe, T. and Nagai, S. : Geological factor of the Ushikagi tunnelling collapse, Proc. of Japan Sciory of Engineering Geology, pp.89-92, 2006. (In Japanese)

11) Heinrich, H.W., Petersen, D. and Roos, N. : Industrial accident prevention (5th ed.), New York, McGraw-Hill, 1980.

12) Marhavilas, P.K., Koulouriotis, D.E., Mitrakas, C.: On the development of a new hybrid risk assessment process using occupational accidents' data: Application on the Greek Public Electric Power Provider, Journal of Loss Prevention in the Process Industries, pp.671-687, 2011.

(Received May 18, 2015) 